\title{
PEMULIHAN KUAT TEKAN BETON RINGAN BERSERAT ALUMINIUM PASCA BAKAR DENGAN VARIASI WAKTU WATER CURING
}

\author{
Antonius Mediyanto' ${ }^{1)}$, Endah Safitri ${ }^{2)}$ \\ 1), 2)Jurusan Teknik Sipil Fakultas Teknik UNS, Jl. Ir. Sutami No. 36 A Surakarta, Telp (0271) 634524 \\ Email : mediyantoantonius@gmail.com
}

\begin{abstract}
Abstrak
Tujuan penelitian ini adalah untuk mengevaluai pemulihan kuat tekan beton ringan berserat aluminium pasca bakar dengan variasi waktu water curing. Benda uji berupa silinder dengan diameter $150 \mathrm{~mm}$ dan tinggi 300 $\mathrm{mm}$. Bahan penelitian : serat aluminium dengan aspek rasio sebesar 60 dengan panjang $50 \mathrm{~mm}$, semen tipe I, pasir, alwa, air, dan viscocrete. Pengujian berdasarkan SK SNI S-36-1990-03. Dalam penelitian ini proses pemulihan (recovery) sampai waktu 56 hari setelah pembakaran mampu meningkatkan nilai kuat tekan sebesar $144,59 \%$ untuk beton ringan, sedangkan untuk beton ringan berserat aluminium peningkatan nilai kuat tekannya sebesar 82,26\%. Hal ini berarti proses pemulihan (recovery) sampai waktu 56 hari mampu mengembalikan kekuatan beton seperti sebelum dibakar.
\end{abstract}

\begin{abstract}
The research concerns on strength of lightweight concrete with aluminium fiber as micro-reinforcement by environmental load especially burning and water curing. In this research cylindrical concrete of $150 \mathrm{~mm}$ dia, $300 \mathrm{~mm}$ high for compressive test. Fiber volume fraction are $0,75 \%$ of concrete. Aluminium fiber with aspect ratio 60, cement type I, sand, alwa, water, and viscocrete are used. Testing are based on SK SNI S-36-1990-03. The result shows that increasing self recovery of average compressive strength of cylindrical concrete is 144.59 $\%$ and $82.26 \%$ on light weight concrete and aluminium fiber light weight concrete with water curing for 56 days. Water curing can self healing light weight concrete and aluminium fiber light weight concrete after burning.
\end{abstract}

Key Word : water curing, light weight concrete, burning

\section{LATAR BELAKANG}

Sifat agregat ringan yang porous mengakibatkan tidak kompak, berat jenis agregat ringan lebih kecil dari berat jenis matrik beton ringannya, hal ini mengakibatkan modulus elastisitas agregat ringan juga lebih kecil dari pada matriknya, dan terakhir tingkat kekuatan - kekakuan agregat ringan lebih kecil dari matriknya. Sebagai akibatnya, adalah beton ringan mempunyai kelemahan yang mendasar berkaitan dengan bahan penyusunnya yaitu agregat ringannya.

Perlu diupayakan peningkatan kinerja agregat ringan agar dapat mengimbangi kinerja pasta semennya, tetapi tetap ringan. Pemakaian serat sebagai bahan tambah pada beton ringan merupakan sebuah solusi atas penomena bahwa beton ringan lebih getas dari pada beton normal, seperti dilaporkan oleh Mediyanto dkk. (2004, 20092011) bahwa serat serat aluminium telah dapat meningkatkan kuat tekan, kuat belah, MOR dengan meningkatkan kualitas matriknya baik karena proses fiber bridging, dowel action, dan aksi kompositnya. Berdasarkan penelitian tersebut, serat aluminium mampu empowering bahan beton ringan berupa peningkatan kuat tekan, modulus elastisitas, kuat tarik-belah, MOR dan meningkatkan kinerja balok beton-bertulangringan berupa peningkatan kapasitas lentur, daktilitas, dan kapasitas gesernya. Ini bukti pemakaian serat sebagai bahan tambah pada beton ringan merupakan sebuah solusi atas penomena bahwa beton ringan lebih getas dari pada beton normal.

Ide yang melatar belakangi penelitian ini adalah:

1. sifat isolasi agregat ringan ini dimanfaatkan untuk melindungi lapis material di sisi dalamnya pada saat kebakaran.

2. sifat serat yang akan menahan beban yang seharusnya ditransfer ke agregat ringan ketika agregat mulai melunak akibat suhu yang ada.

3. sifat serat yang akan memperbaiki kwalitas matrik beton ringan terhadap beban tekan maupun tarik.

4. sifat water curing yang diharapkan dapat meningkatkan kekuatan dan durabilitas matrik beton ringan terhadap beban (load), termasuk beban zat kimia dari lingkungannya, gesekan, dan kejut. 
Pokok pikiran penelitian ini berorientasi secara khusus pada kemungkinan peningkatan kwalitas material beton ringan dengan mempelajari fenomena isolasi suhu, penjebatanan serat, dan aksi pasak seratnya karena penambahan serat, terutama pada kondisi pra bakar, paska bakar, dan setelah mendapatkan perawatan/pembasahan air dengan berbagai intensitas selama 14 hari, 28 hari, 42 hari, dan 56 hari untuk mendapatkan data waktu minimal dimana didapat pemulihan maksimal, mengingat perawatan dengan pembasahan air selama 28 hari pada beton ringan metakaolin berserat aluminium pasca bakar, Mediyanto dkk. (2009-2011), dapat meningkatkan kuat tekan rata-rata, modulus elastisitas rata-rata, kuat belah rata-rata, dan modulus runtuh rata-rata berturut-turut sebesar ; 38,46\%, 44,47 \%, 85,12\%, dan 25,21\%. Ini berarti bahwa usaha pembasahan dengan air membantu pemulihan tubermorit (CSH) sebagai unsur yang menentukan kekuatan beton perlu dikaji secara mendalam.

\section{TINJAUAN PUSTAKA}

Water curing pada beton berpenguh kuat pada ; final strength, shrinkage, cracking, abrasion, absorbtion, penetration, and surface apperance, Bahri (2010). Hal-hal yang berpengaruh pada keberhasilan water curing adalah; time of curing, humidity of curing, and temperatrur of curing, Roosyanto (2010).

Pembasahan dengan air beton pasca bakar, mengembalikan kekuatan dengan membangun $\beta C S H$ dalam kristalnya, Partowiyatmo dan Sudarmadi (2004), Sambowo dan Mediyanto (2008).

Perawatan dengan pembasahan air selama 28 hari pada beton ringan metakaolin berserat aluminium, Mediyanto dkk. (2009-2011), dapat meningkatkan kuat tekan rata-rata, modulus elastisitas rata-rata, kuat belah rata-rata, dan modulus runtuh rata-rata sebesar berturut-turut $38,46 \%, 44,47 \%, 85,12 \%$, dan $25,21 \%$. Ini berarti bahwa usaha pembasahan dengan air membantu pemulihan tubermorit (CSH) sebagai unsur yang menentukan kekuatan beton perlu dikaji secara mendalam.

Dalam penelitian ini dilakukan perawatan/pembasahan air dengan berbagai intensitas selama 14 hari, 28 hari, 42 hari, dan 56 hari untuk mendapatkan waktu minimum agar didapat pemulihan maksimal.

Sifat tahan api (fire resistance) unsusr-unsur bangunan secara umum diukur dan ditetapkan menurut standar ASTM E 119. Daya tahan didefinisikan sebagai lamanya bahan bertahan terhadap kebakaran standar sebelum titik kritis akhir pertama dicapai. Sifat-sifat fisik baja dan beton akan dipengaruhi oleh factor lingkungan, diantaranya adalah suhu. Pada suhu yang sama dengan suhu yang dijumpai pada kebakaran, kekuatan dan modulus elastisitas berkurang.

Sisa tegangan beton ringan dalam $\%$ dari nilai awal akibat kenaikan suhu berturut-turut; $200^{\circ} \mathrm{C}, 300^{\circ} \mathrm{C}, 400^{\circ} \mathrm{C}$, $500^{\circ} \mathrm{C}, 600^{\circ} \mathrm{C}, 650^{\circ} \mathrm{C}, 700^{\circ} \mathrm{C}, 800^{\circ} \mathrm{C}$, dan $850^{\circ} \mathrm{C}$ adalah berturut-turut; $95 \%, 92 \%, 90 \%, 85 \%, 90 \%, 95 \%, 75 \%$, $60 \%$ dan 50\% (Abram, 1987).nSisa modulus elastisitas beton ringan dalam \% dari nilai awal akibat kenaikan suhu berturut-turut; $200^{\circ} \mathrm{C}, 300^{\circ} \mathrm{C}, 400^{\circ} \mathrm{C}, 500^{\circ} \mathrm{C}, 600^{\circ} \mathrm{C}$, dan $700^{\circ} \mathrm{C}$, adalah berturut-turut; $65 \%, 55 \%, 40 \%$, $38 \%, 35 \%$,dan $30 \%$ (Cruz, 1987). Angka muai beton ringan akibat kenaikan suhu berturut-turut; $200^{\circ} \mathrm{C}, 300^{\circ} \mathrm{C}$, $400^{\circ} \mathrm{C}, 500^{\circ} \mathrm{C}, 600^{\circ} \mathrm{C}, 700^{\circ} \mathrm{C}$, dan $800^{\circ} \mathrm{C}$ adalah berturut-turut; $0,0011,0,0020,0,0027,0,0040,0,0051,0,0062$, dan 0,0073 (Gustafero, 1987).

Lebih jauh Gustaferro menjelaskan bahwa beton bertulang structural yang menerus atau bersifat statis tak tentu akan mengalami perubahan tegangan bila terbakar. Perubahan tegangan ini diakibatkan oleh gradient suhu dalam elemen-elemen structural atau perubahan kekuatan bahan-bahan struktural pada suhu tinggi, atau keduanya.

Partowiyatmo dan Sudarmadi (2004) melaporkan bahwa kekuatan sisa dari beton struktur yang habis mengalami pendinginan setelah terbakar akan tergantung dari suhu tertinggi selama kebakaran berlangsung, campuran yang digunakan dan kondisi pembebanan selama mengalami kebakaran. Disamping itu, karena karakteristik dari perpindahan panas maka hanya temperature di bagian terluar yang meningkat sangat drastic sementara dibagian dalam temperature lebih rendah, tergantung dari kedalaman dari kulit terluar. Sebagai contoh dalam penelitian Amir dan Sudarmadi dengan benda uji kolom 30 x 40 x $1500 \mathrm{~cm}^{3}$ yang mengalami pemanasan sampai dengan suhu $1000^{\circ} \mathrm{C}$, di bagian kulit beton suhunya mencapai $835^{\circ} \mathrm{C}$. Akan tetapi temperature di dalam beton masingmasing hanya $150^{\circ} \mathrm{C}$ untuk kedalaman $7,5 \mathrm{~cm}$ dan $100^{\circ} \mathrm{C}$ untuk kedalaman $10 \mathrm{~cm}$ walaupun tulangan baja yang berjarak $2,5 \mathrm{~cm}$ bertemperatur cukup tinggi $650{ }^{\circ} \mathrm{C}$. Hal ini menunjukan bahwa suhu luar pembakaran dapat jauh berbeda dengan suhu/temperature di dalam beton. Hal ini pula yang menjadikan penelitian ini sangat menarik, khususnya perubahan sifat dan kekuatan tulangan baja dalam beton ringan dengan berbagai variasi bahan tambah didalamnya. 
Teori penulangan dalam mekanika retak berdasarkan pada kekuatan dari serat mencakup: (1) menitik beratkan lekatan dan penjangkaran, (2) memerlukan serat yang kuat dan kaku, (3) retak sepanjang serat, dan (4) banyaknya kerusakan matrik beton. Zollo (1997) menyatakan bahwa penggunaan serat pada beton bertulang dapat meningkatkan penyerapan energi, daktilitas, mengendalikan retak, dan meningkatkan sifat deformasi.

Dari beberapa penelitian terdahulu, pemberian serat di dalam struktur beton memberi kontribusi positif terhadap kenaikan kekuatan tariknya. Tipe serat secara umum dapat diklasifikasikan menjadi empat menurut ACI Comitte 544.

1. SFRC ( Steel Fiber Reinforced Concrete)

2. GFRC ( Glass Fiber Reinforced Concrete)

3. SNFRC ( Synthetic Fiber Reinforced Concrete)

4. NFRC ( Natural Fiber Reinforced Concrete).

Penelitian yang dilakukan oleh Suhendro (1991) membuktikan bahwa sifat-sifat kurang baik dari beton, yaitu getas, praktis tidak mampu menahan tegangan tarik dan momen lentur dapat diperbaiki dengan menambahkan fiber lokal yang terbuat dari potongan-potongan kawat pada adukan beton. Selain itu dibuktikan pula bahwa tingkat perbaikan yang diperoleh dengan menggunakan fiber lokal tidak kalah dengan hasil-hasil yang dilaporkan di luar negeri dengan menggunakan steel fiber yang asli.

\section{HASIL PENELITIAN DAN PEMBAHASAN}

Pasir

Pasir yang digunakan adalah pasir yang diuji berdasarkan pada standar ASTM dengan kandungan lumpur sebesar 2,3\%. Pasir ini termasuk dalam kelompok daerah II dan dalam tabel gradasi dengan modulus halus pasir sebesar 2,50. Berat jenis dalam kondisi jenuh kering muka (Saturated Surface Dry, SSD) adalah 2,50 t/m 3 . Sementara itu serapan air sebesar $0,95 \%$.

\section{ALWA (Artificial Lightweight Aggregate)}

ALWA merupakan agregat ringan yang terbuat dari lempung sedimenter yang telah mengalami proses pemanasan pada tungku (clinker) dengan suhu antara $500^{\circ} \mathrm{C}$ sampai dengan $1200^{\circ} \mathrm{C}$. Lempung sedimenter yang dipanaskan ini akan membuat kandungan silika mengeras dan menyelimuti butiran sehingga mengeras dan dapat digunakan sebagai agregat ringan beton. ALWA yang dipakai dalam penelitian ini merupakan hasil produksi UPT Puskim, Cilacap dengan data teknik ALWA yang dapat dilihat pada tabel 1.

\begin{tabular}{lc}
\multicolumn{2}{c}{ Tabel 1 Data Teknik ALWA } \\
\hline Berat jenis & $0,45-0,75 \mathrm{~kg} / \mathrm{L}$ \\
Berat jenis kering mutlak & $0,75-1,2$ \\
Resapan air & $16,5-20 \%$ \\
Volume padat & $58-62 \%$ \\
Isi terapung & $3-91 \%$ \\
Modulus halus & $5-7 \%$ \\
Abrasi & $48-53 \%$ \\
\hline
\end{tabular}

Komposisi kimia ALWA yang dipakai pada penelitian ini adalah $\mathrm{SiO}_{2}$ sebanyak 55\%, $\mathrm{Al}_{2} \mathrm{O}_{3}: 20,4 \%, \mathrm{Fe}_{2} \mathrm{O}_{3}$ : 6,8\%, MgO: 2,4\%, $\mathrm{CaO}: 1,8 \%, \mathrm{Na}_{2} \mathrm{O}: 2 \%, \mathrm{~K}_{2} \mathrm{O}: 2-3 \%$. Berat jenis dalam kondisi jenuh kering muka (Saturated Surface Dry, SSD) adalah $1,48 \mathrm{t} / \mathrm{m}^{3}$. Sementara itu serapan air sebesar $1,38 \%$.

\section{Serat Alumunium}

Serat alumunium dapat memperbaiki kuat tarik beton karena mempunyai berat jenis sebesar $2,12 \mathrm{t} / \mathrm{m}^{3}$ dengan tegangan maksimum $100 \mathrm{MPa}$ dan perpanjangan $11 \%$. Serat alumunium yang dipakai dalam penelitian ini berupa potongan-potongan kecil yang rata-rata berukuran $2 \mathrm{~mm}$ x $50 \mathrm{~mm}$.

\section{Hasil Pengujian Kuat Tekan Beton}

Pengujian kuat tekan beton ringan menggunakan mesin CTM (Compressing Testing Machine) dengan kecepatan yang stabil, pengujian dilakukan pada saat benda uji berumur 28 hari. Kuat tekan dihitung dari beban desak dibagi luas penampang bidang desak. 


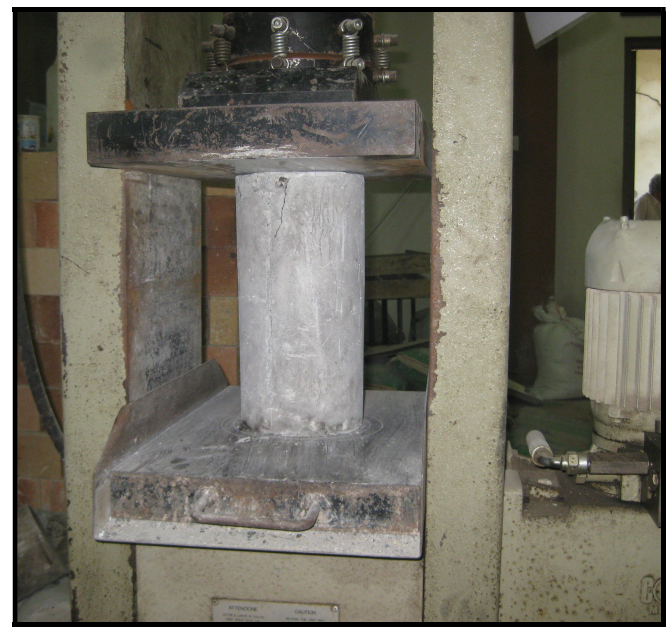

Gambar 1. Pengujian kuat tekan

Hasil analisa kuat tekan rata-rata pada penelitian ini adalah sebagai berikut :

Untuk beton ringan nilai kuat tekan rata-ratanya adalah :

a. Sebelum Pembakaran : $20.92 \mathrm{Mpa}$

b. Pembakaran $500^{\circ} \mathrm{C}: 17.81 \mathrm{Mpa}$

c. Pembakaran $500^{\circ} \mathrm{C}+$ Curing 14 hari : $27.43 \mathrm{Mpa}$

d. Pembakaran $500^{\circ} \mathrm{C}+$ Curing 28 hari : $19.37 \mathrm{Mpa}$

e. Pembakaran $500^{\circ} \mathrm{C}+$ Curing 42 hari : $19.13 \mathrm{Mpa}$

f. Pembakaran $500^{\circ} \mathrm{C}+$ Curing 56 hari : $30.26 \mathrm{Mpa}$

Untuk beton ringan berserat aluminium nilai kuat tekan rata-ratanya adalah :
a. Sebelum Pembakaran : $17.53 \mathrm{Mpa}$

b. Pembakaran $500^{\circ} \mathrm{C}: 13.01 \mathrm{Mpa}$

c. Pembakaran $500^{\circ} \mathrm{C}+$ Curing 14 hari : $13.01 \mathrm{Mpa}$

d. Pembakaran $500^{\circ} \mathrm{C}+$ Curing 28 hari : 8.48 Mpa

e. Pembakaran $500^{\circ} \mathrm{C}+$ Curing 42 hari : $13.48 \mathrm{Mpa}$

f. Pembakaran $500^{\circ} \mathrm{C}+$ Curing 56 hari : $14.42 \mathrm{Mpa}$

Proses water curing setelah beton dibakar menyebabkan meresapnya air kedalam pori-pori beton dan bereaksi dengan senyawa $\mathrm{C}_{2} \mathrm{~S}$ dan $\mathrm{C}_{3} \mathrm{~S}$ pada butiran-butiran semen yang belum bereaksi maupun senyawa $\alpha \mathrm{C}_{2} \mathrm{~S}$ pada semen akibat beton terbakar, hasil reaksi dari senyawa tersebut menjadi C-S-H dan $\mathrm{Ca}(\mathrm{OH})_{2}$ sehingga mampu mengembalikan kekuatan beton seperti sebelum terbakar (Partowiyatmo, 2005). Dalam penelitian ini proses pemulihan (recovery) sampai waktu 56 hari setelah pembakaran mampu meningkatkan nilai kuat tekan sebesar $144,59 \%$ untuk beton ringan, sedangkan untuk beton ringan berserat aluminium peningkatan nilai kuat tekannya sebesar 82,26\%. Hal ini berarti proses pemulihan (recovery) sampai waktu 56 hari mampu mengembalikan kekuatan beton seperti sebelum dibakar.

\section{KESIMPULAN}

Dari pembahasan hasil penelitian tersebut dapat disimpulkan :

Pemulihan maksimal kuat tekan, didapat pada perawatan 56 hari.

Ucapan terimakasih kepada Dikti yang telah berkenan membiayai penelitian ini.

\section{DAFTAR PUSTAKA}

ACI 318-95 (1996), "Building Code Requirements for Reinforced Concrete", ACI Manual of Concrete Practice, Part 3: Use of Concrete in Building - Design, Specification, and Related Topics, Detroit, Michigan, 345 pp.

Anonim, SNI 03 - 2847 - 2002, Tata cara perhitungan struktur beton untuk bangunan gedung. 
ASTM Designation: E119-83 (1983), Standard Methods of Fire Tests of Building Construction and Materials, Vol. 04.07, 1983 Annual Book of Standards, American Society for Testing and Materials.

Bahri, S. (2010), Durability of concrete, mechanisms and influencing factors, Seminar of concrete application for sustainable construction, pp 2, Jurusan Teknik Sipil, Fakultas Teknik, UNS.

Callister,W.,D.,(1997), Materials Science \& Engineering, John Wiley \& Sons, Inc.

Gustaferro, A. H. (1987), Fire Resistance, Handbook of Concrete Engineering (Ed. Mark Fintel), Van Nostrand Reinhold Company, New York, 1 - 40.

Mediyanto,A., Hartono, W., (2003), "Kapasitas momen kolom tampang bundar yang diperkuat dengan carbon fiber reinforced plastic-plate", Jurusan Teknik Sipil, Fakultas Teknik UNS.

Mediyanto, A., Senot Sangaji, Sudarmoko, Andreas Triwiyono, (2004), Kajian sifat mekanik dan kapasitas elemen structural beton ringan berserat aluminium. Penelitian Hibah Pekerti, UNS.

Mediyanto,A.,Safitri,E., Sapto,P.,(2009-2011), Model prediksi kapasitas kolom beton ringan-metakaolin berserat aluminium paska bakar. Jurusan Teknik Sipil, Fakultas Tekni UNS.

Partowiyatmo, A. and Sudarmadi (2004), "Strength Recovery of Fire Concrete", Proceedings of the $7^{\text {th }}$ International Conference on Quality in Research (QIR), University of Indonesia, Jakarta. 6 pp.

Roosyanto,S. (2010), Specifyng cement for use in applications, Seminar of concrete application for sustainable construktion, $p p$ 7, Jurusan Teknik Sipil, Fakultas Teknik, UNS.

Sambowo, K.A., dan Mediyanto,A.,(2008), Model prediksi kapasitas balok beton ringan-metakaolin berserat aluminium paska bakar. Jurusan Teknik Sipil, Fakultas Tekni UNS.

Suhendro, B. (1992), "Pengaruh Pemakaian Fiber Secara Parsial pada Perilaku dan Kapasitas Balok Beton Bertulang", Seminar Mekanika Bahan Untuk Meningkatkan Potensi Bahan Lokal, PAU UGM.

Zollo, R.F. (1997), Fiber Reinforced Concrete: an overview after 30 years of development, Cemen and Concrete Composite, Vol.19, pp 107-122. 